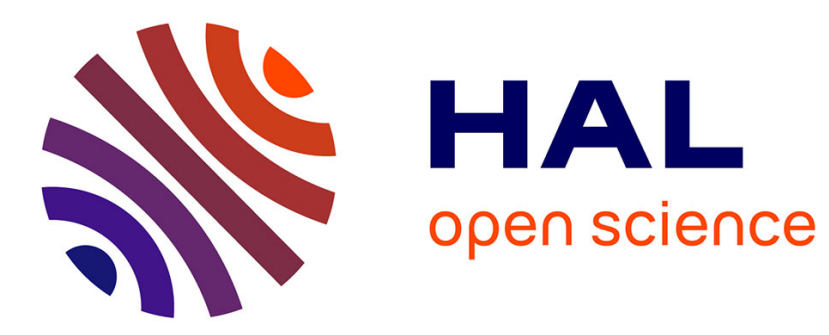

\title{
Geographic variation in marmots' alarm calls causes different responses
}

Thierry Lengagne, Mariona Ferrandiz-Rovira, Clara Superbie, Irene Figueroa, Coraline Bichet, Bernat Claramunt-Lopez, Aurélie Cohas

\section{- To cite this version:}

Thierry Lengagne, Mariona Ferrandiz-Rovira, Clara Superbie, Irene Figueroa, Coraline Bichet, et al.. Geographic variation in marmots' alarm calls causes different responses. Behavioral Ecology and Sociobiology, 2020, 74 (8), 10.1007/s00265-020-02858-5 . hal-02975219

\section{HAL Id: hal-02975219 \\ https://univ-lyon1.hal.science/hal-02975219}

Submitted on 4 Jan 2021

HAL is a multi-disciplinary open access archive for the deposit and dissemination of scientific research documents, whether they are published or not. The documents may come from teaching and research institutions in France or abroad, or from public or private research centers.
L'archive ouverte pluridisciplinaire HAL, est destinée au dépôt et à la diffusion de documents scientifiques de niveau recherche, publiés ou non, émanant des établissements d'enseignement et de recherche français ou étrangers, des laboratoires publics ou privés. 


\section{Behavioral Ecology and Sociobiology Geographic variations in marmots' alarm calls cause different responses --Manuscript Draft--}

Manuscript Number:

Full Title:

Article Type:

Corresponding Author:

Order of Authors:

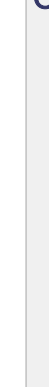

\section{Corresponding Author Secondary} Information:

Corresponding Author's Institution:

Corresponding Author's Secondary Institution:

First Author:

Thierry Lengagne

First Author Secondary Information:

Order of Authors Secondary Information:

\section{Funding Information:}

Abstract:

Suggested Reviewers:

Original Article

Thierry Lengagne

Clara Superbie

Irene Figueroa

Coraline Bichet

Aurélie Cohas de Recerca
(2017 SGR 1006)

James F Hare
BEAS-D-19-00269

Geographic variations in marmots' alarm calls cause different responses

Mariona Ferrandiz-Rovira

Universitat Autònoma de Barcelona

Bellaterra, Catalunya SPAIN

Mariona Ferrandiz-Rovira

Bernat Claramunt-Lopez

Universitat Autònoma de Barcelona

Agència de Gestió d'Ajuts Universitaris i Not applicable

Population differences in acoustic signals, have been investigated for five decades to better understand the evolution of communication. When receivers are able to discriminate among signals and to react accordingly, geographic differences can have major impacts on the ability of conspecifics to communicate. Surprisingly, population differences in alarm calls and their consequences on the communication process have been so far neglected despite their crucial role on individuals' survival. Working with four wild populations of Alpine marmots (Marmota marmota), we found differences in the acoustic structure of their alarm calls. These differences can neither be explained by geographic, nor genetic distances but rather by other mechanisms including random processes. Moreover, playback experiments provided evidence that receivers discriminate among alarm calls from their own versus other populations, with responses being lower in intensity when the call bout played back originated from their own population. Research on the mechanistic causes of geographical markers and on the relationship between geographical variation, reliability of the signal and behavioural responses are now required to better understand how predation pressure and natural selection could drive the evolution of communication.

James.Hare@umanitoba.ca

He already reviewed a previous version of the manuscript

Dan Blumstein

marmots@ucla.edu

He already reviewed a previous version of this manuscript 


\begin{tabular}{|l|l|}
\hline & $\begin{array}{l}\text { C. N. Slobodchikoff } \\
\text { Con.SlobodchikoV@nau.ed }\end{array}$ \\
\hline $\begin{array}{l}\text { Roberto A. Delgado } \\
\text { roberto.delgado@hunter.cuny.edu }\end{array}$ \\
\hline $\begin{array}{l}\text { E. Geffen } \\
\text { geffene@post.tau.ac.il }\end{array}$ \\
\hline $\begin{array}{l}\text { SANDRA ANNE BANACK } \\
\text { sbanack@fullerton.edu }\end{array}$ \\
\hline Opposed Reviewers: & \\
\hline
\end{tabular}




\section{Geographic variations in marmots' alarm calls cause different}

\section{2 responses}

3

4 Thierry Lengagne ${ }^{1}$, Mariona Ferrandiz-Rovira ${ }^{2,3,4}$, Clara Superbie $^{2,5}$, Irene Figueroa3 ${ }^{, 4}$,

5 Coraline Bichet ${ }^{6}$, Bernat Claramunt-Lopez ${ }^{3,4}$, Aurélie Cohas ${ }^{2}$

6

$7 \quad{ }^{1}$ Laboratoire Ecologie des Hydrosystèmes Naturels et Anthropisés, Université de Lyon ;

8 ENTPE, CNRS, Université Lyon1, 6 Rue Raphaël Dubois 69622 Villeurbanne, France.

9 22Laboratoire Biométrie et Biologie Évolutive, Université de Lyon, CNRS, UMR 5558,

10 Université Lyon 1, 69622, Villeurbanne, Lyon 69000, France

$11{ }^{3}$ CREAF, Cerdanyola del Vallès 08193, Catalonia

$12{ }^{4}$ BABVE Universitat Autònoma de Barcelona, Cerdanyola del Vallès 08193, Catalonia

$13{ }^{5}$ Department of Biology, University of Saskatchewan, 112 Science Place, Saskatoon, SK

14 S7N 5E2, Canada

15 'Institut für Vogelforschung "Vogelwarte Helgoland" (Institute of Avian Research),

16 Wilhelmshaven, Germany

17

18

19 Authors for correspondence:

20 Thierry Lengagne, e-mail: thierry.lengagne@univ-lyon1.fr

21 Mariona Ferrandiz, e-mail: mariona.ferrandiz@uab.cat

22

23 ORCID Mariona Ferrandiz-Rovira ID https://orcid.org/0000-0001-8548-2851 


\section{Abstract}

25 Population differences in acoustic signals, have been investigated for five decades to 26 better understand the evolution of communication. When receivers are able to

27 discriminate among signals and to react accordingly, geographic differences can have 28 major impacts on the ability of conspecifics to communicate. Surprisingly, population

29 differences in alarm calls and their consequences on the communication process have 30 been so far neglected despite their crucial role on individuals' survival. Working with

31 four wild populations of Alpine marmots (Marmota marmota), we found differences in

32 the acoustic structure of their alarm calls. These differences can neither be explained by 33 geographic, nor genetic distances but rather by other mechanisms including random 34 processes. Moreover, playback experiments provided evidence that receivers 35 discriminate among alarm calls from their own versus other populations, with responses 36 being lower in intensity when the call bout played back originated from their own 37 population. Research on the mechanistic causes of geographical markers and on the 38 relationship between geographical variation, reliability of the signal and behavioural 39 responses are now required to better understand how predation pressure and natural 40 selection could drive the evolution of communication.

\section{Significance statement}

42 Dialects can have major impacts on the ability of conspecifics to communicate.

43 Surprisingly, dialects in alarm calls have been neglected despite their crucial role on

44 individuals' survival. Alpine marmots have dialects in alarm calls and do discriminate

45 their own dialects from others, being more frightened by alarm calls from another 46 population than their own. Confronted with an unknown dialect, marmots may adopt a 
47 self-preserving strategy and chose to run-away before assessing the danger.

49 Keywords: acoustic communication; dialect; genetic differentiation; geographic 50 variation; alarm call

51

\section{Acknowledgements}

53 We thank all the students involved in marmot recording. We are grateful to the golf of

54 Tignes for allowing us to work on its green. We are deeply grateful to the commune of 55 Tignes for the use of the Santel chalet. In the Pyrenees, we warmly thank all the people 56 involved in field campaigns and special thanks to A. Planella and M. Unzeta (supported 57 by a COLAB grant from the Catalan Government). MFR thanks the Generalitat de 58 Catalunya (2017 SGR 1006). We further acknowledge James F. Hare, Dan Blumstein 59 and two anonymous reviewers for helpful and constructive comments and suggestions 60 that helped us to improve a previous version of this paper. 


\section{Introduction}

62 Considerable geographic differences among populations in acoustic signals, usually

63 termed dialects, geographic markers or geographic variations (Conner 1982), have been

64 documented across the whole animal kingdom (in mammals (Lameira et al. 2010); in

65 birds (Krebs et al. 1980); in anurans (Velásquez 2014); in fish (Parmentier et al. 2005);

66 in invertebrates (Zuk et al. 2001); for review, see (Wilczynski and Ryan 2001). This

67 signal variation could arise from various processes, such as genetic and/or cultural drifts

68 between isolated populations (Baker 1982; Davidson and Wilkinson 2001; Mundinger

69 1982; Janik and Slater 2003), and are particularly relevant to our understanding of the

70 divergent evolution in communication systems (Campbell et al. 2010; Wilczynski and

71 Ryan 2001). Signals have been shown to be influenced by many factors, including

72 geographic barriers (Thomas et al. 1988; Cleator et al. 1989; Thomas et al. 1992; Perry

73 and Terhune 1999), environment (, habitat structure, background noise (Hunter and

74 Krebs 1979; Wiley and Richards 1982; van Parijs et al. 2003; Nichols and Goldizen

75 2006)) and sexual selection (e.g., female preferences (Slater 1986)).

76 Signal geographic variation implies a structural variation from the emitter point

77 of view but must also involve detection and discrimination processes by the receiver to

78 have a major impact on the ability of conspecifics to communicate. For instance, an

79 extensive literature on songbirds shows that dialects can strongly affect breeding

80 behaviour, especially mate attraction and intra-sexual competition (Searcy et al. 2002).

81 Many studies suggest that individuals discriminate among songs from conspecific

82 populations, preferring the signal of their local population in a context of mate choice

83 and intra-sexual competition (Baker 1982; Searcy et al 2002; Gray 2005; Boul et al

84 2007; Podos 2007; Nichols 2008; Uy et al. 2009; Bradely et al. 2013; Mortega et al. 
85 2014; Lin et al. 2016); even in close populations (Leader et al. 2002; but see Colbeck et

86 al. 2010; Danner et al. 2011). Dialects can then act as pre-zygotic barriers and play an

87 important role in speciation (Baker and Cunningham 1985; Slabbekoorn and Smith

88 2002; Price 2008; Wilkins et al. 2013). Similar patterns and processes have been

89 suggested in mammals, although evidence is much more limited (Maeda and Masataka

90 2010).

91 Studies investigating geographic variation in acoustic signals and its perception

92 in behavioural contexts other than sexual selection in avian species remain scarce

93 (Charrier et al. 2013). Alarm calls, shaped by natural selection, could be as relevant to

94 speciation as acoustic sexual signals because of their direct consequences on

95 individuals' survival. Despite this crucial role, dialects in alarm calls have been so far

96 poorly investigated because they are not as complex as bird nuptial and territorial songs.

97 Although some of them are sophisticated (e.g., syntax in mobbing calls (Suzuki 2016);

98 complex signal structure in monkey screams (Zuberbühler 2009)), alarm calls are often

99 a repetition of one same call unit (Randler et al. 2011). Both the structure of the note

100 and its repetition rate can be used to encode information (Manser 2001, but see Rendall

101 et al. 2009). Nevertheless, it has been shown that alarm calls with highly stereotyped

102 structures can convey information about the age or the sex of the emitter (Blumstein and

103 Muñoz 2005). Geographic differences in alarm calls have been documented in several

104 mammalian species (Slobodchikoff et al 1998; Matrosova et al. 2012; Schlenker et al.

105 2014, Francescoli 2002; Eiler and Banack 2004) but were found sometimes absent in

106 yellow-bellied marmots, Marmota flaviventris (Blumstein and Armitage 1997). When

107 present, their perceptual salience remains unknown (Zuberbühler 2009). Hence the

108 importance of such variation for the communication process is currently unknown and 
109 further playback experiments are necessary to determine their biological relevance.

We investigated the existence of structural differences in alarm calls produced

111 by Alpine marmots (Marmota marmota) from two native (Alps) and two reintroduced

112 (Pyrenees) populations, and whether receivers discriminate among them. Alpine 113 marmots are cooperatively breeding ground-dwelling territorial squirrels living in

114 family groups. Territory surveillance is insured by all individuals from a family and, 115 once a predator is detected, marmots can produce alarm calls warning other individuals 116 before hiding in their burrows (Perrin et al. 1993). Marmot alarm calls are usually 117 composed of one stereotyped and frequency modulated single note (Perrin et al. 1993). 118 The comparison between the native populations in the Alps and the reintroduced 119 populations in the Pyrenees is of particular interest to investigate the relationship 120 between signal divergence and genetic differentiation, as well as their consequences in 121 terms of between-population recognition. We first investigated whether geographic 122 variations are encoded in the acoustic structure of alarm calls produced by marmots 123 from the four studied populations. Although dynamic interplay between song learning 124 mechanisms and geographic isolation have been evidenced to be at the origin of dialects 125 in birds songs (Podos and Warren 2007), the processes underlying the evolution of 126 alarm call dialects remains to be described. Moreover, due to the fact that songs in 127 oscines are usually learned (Kroodsma 2004), song dialects have been found to result 128 from short-term, cultural, or ecological processes rather than to have a genetic basis 129 (e.g., Halfwerk and Slabbekoorn 2009; Ruegg et al. 2006). Conversely, alarm calls 130 structure have a substantial genetic basis (Blumstein 2007; Blumstein et al. 2013) and 131 consequently, cultural drift is unlikely to occur. Therefore, we expect to observe a strong 132 relationship between alarm call divergence and genetic differentiation between the two 
133 reintroduced populations, which are geographically and genetically isolated from the 134 two native populations (Bichet et al. 2016). We also conducted playback experiments to 135 determine whether receivers perceived the differences in alarm calls produced by 136 different populations and changed their anti-predatory response.

138 Methods

\section{Ethical Note}

140 Fieldwork was conducted under permit number AP n82010/121 by the Préfecture de la

141 Savoie. All handling and sampling were done by three co-authors who are authorized

142 for experimentation with animals by the French Ministry of Agriculture and Fisheries or

143 Catalan Government (diplomas 0ETRY20090520, R45GRETAF110 and 53707-UAB-

144 FELASA). The protocol was approved by the ethical committee of the University of 145 Claude Bernard Lyon 1 (n8BH2012-92 V1).

\section{Study populations}

148 We studied Alpine marmots from four populations (Supplementary Material S1): 149 Sassière and Tignes are native populations of the Western Alps located $10 \mathrm{~km}$ apart, 150 while Cerdanya (La Bastida) and Ripollès (Pardines) are reintroduced (from 1948 until 151 1988, Couturier 1955; Ramousse et al. 1992) populations situated $500 \mathrm{~km}$ away from 152 the first ones in the South-eastern Pyrenees and which are $45 \mathrm{~km}$ apart. Ripollès is 153 genetically closer to the two native populations than Cerdanya (Bichet et al. 2016). 154 Within each population, intensive behavioural observations allowed us to precisely 155 identify family groups and to locate main burrows and territory borders. To conduct 156 genetic analyses, 151 unrelated individuals were captured in these four populations (all 
157 the details about the sampling and the genetic analyses are given in the Supplementary 158 Material).

\section{Does the acoustic structure of alarm calls differ between populations?}

161 Each year (2011-2014), alarm calls were recorded in the four populations between mid162 April and mid-July from 8:00 a.m. to 6:00 p.m. the main activity period of the marmots. 163 An omnidirectional microphone (Sennheiser ME62-K6P) connected to a Fostex FR2LE 164 recorder (frequency sampling: $44.1 \mathrm{kHz}$, resolution: 16 bits) was placed approximately $1652 \mathrm{~m}$ from a main burrow entrance in order to maximize the chances to record alarm 166 calls. Once a recording was performed, we moved to another territory not adjacent to 167 the previous one to record another individual (Sassière: $\mathrm{N}=38$ alarm calls; Tignes: $\mathrm{N}$ $168=31$; Cerdanya: $\mathrm{N}=92$ and Ripollès; $\mathrm{N}=35$ ), Marmots typically retreated into their 169 burrows during the setup of the recording material but they re-emerged within few 170 minutes. Then, individuals were exposed to a threatening situation in order to trigger the 171 emission of alarm calls by a focal individual: a human or a human with a domestic dog 172 (Canis lupus familiaris) appeared promptly from a hide situated 60 to $80 \mathrm{~m}$ away from 173 burrows and ran in the direction of the marmot. This protocol worked in almost all 174 cases. Alarm callers were aged up to 3 years (when they reach adult size and stop 175 growing), which enabled us to distinguish three age classes: pups, yearlings and adults. 176 Since body size and age might impact frequencies of vocalizations neither pups' nor 177 yearlings' calls were analysed (Tubaro and Mahler 1998; Blumstein and Munos 2005; 178 but see Matrosova et al. 2007). As marmots are monomorphic, it was not possible to sex 179 the recorded emitters. Hence, if sex variation is present in the alarm call of Alpine 180 marmot, there will likely be "noise" in our analysis. A sex difference could bias our 
181 analysis at the population level in case of (i) an acoustic difference among male and 182 female which is currently not known in Alpine marmot, (ii) a large difference in the 183 proportion of male and female responding to alarm call playback in our studied 184 populations, and, (iii) a reverse proportion of males and females recorded according to 185 populations. Although an absence of literature does not mean that sex does not play a 186 role in alarm calls. Currently, we do not have evidence for none of the above, but we are 187 confident that sex information did not bias our analysis.

189 They were low-pass filtered to remove all noise corresponding to low frequency (i.e. 190 less than $1 \mathrm{kHz}$, mainly wind noise, Hamming windows, FFT 1024pts). The number of 191 calling bouts recorded varied between individuals and whenever it was possible we 192 processed a maximum of 6 alarm calls per calling bout. From the 38 calling bouts from 193 Sassière, the 31 from Tignes, the 92 from Cerdanya and the 35 from Ripollès, we 194 selected 137, 143, 459 and 145 alarm calls, and described the modulation of their 195 fundamental frequency. For each call, we performed a spectrogram (FFT 1024pts, 196 overlap 93.75\%, Hamming windows, frequency resolution, 47Hz) and we then 197 researched the frequency modulation pattern through a zero crossing analysis. All 198 analysis were performed with the same settings (i.e. same measurements accuracy). The 199 same person (CS) measured on zero crossing the initial, maximum and final frequencies 200 (in $\mathrm{kHz}$ ) and the durations (in $\mathrm{ms}$ ) of the ascendant (AD), stationary (SD) and 201 descendant (DD) phases of the fundamental frequency (Fig. 1). By doing so, we 202 avoided to measure parameters which are highly altered during the propagation. 
205 To test for differences in the acoustic structure of alarm calls between the four 206 populations, we fitted four linear mixed-effect models with either the ascendant phase 207 (AD), the stationary phase (SD), the descendant phase (DD) duration or the initial 208 frequency $(\mathrm{F} 1)$ as the response variable, the population as a fixed effect and the calling 209 bout as a random effect on the intercept. The maximum and final frequencies were 210 discarded due to their strong correlation with the other variables (see Table 1).

211 We then tested for potential differences in the acoustical structure (AD, SD, DD

212 and F1) of alarm calls among the four populations using a Linear Discriminant Analysis

213 (LDA). To further compare each pair of populations, we built six other LDAs. To 214 overcome bias due to uneven sample size between populations, we randomly selected $N$ 215 calls per population without replacement with $N$ equal to the number of alarm calls of 216 the population with the smallest sample size involved in the comparison.

217 Reclassification rates using a cross validation were then calculated with half the data set 218 - the training sample - randomly selected to build the model and the other half - the test 219 sample - used to calculate the percentage of correct classification. The entire procedure, 220 including the random selection of $N$ calls/population, was repeated 1,000 times. We 221 calculated the mean of all obtained percentages of correct classification and their 95\% 222 confidence intervals. We assumed that the acoustic structure differed between the 223 populations if the percentage of correct classification corresponding to a random 224 classification (\%R) was not included in the estimated 95\% confidence intervals.

225 Then, we tested whether the acoustic distance (log-transformed) between 226 populations correlated with either the genetic distance (linearized $\mathrm{F}_{\mathrm{ST}}=\mathrm{F}_{\mathrm{ST}} /\left(1-\mathrm{F}_{\mathrm{ST}}\right)$ ) or 227 the geographic distance (log-transformed) using Mantel tests (all permutations, Mantel 228 1967) implemented in the package vegan (Oksanen et al. 2018). Acoustic distances 
229 between populations were quantified as the pairwise differences in the linear 230 discriminant functions. The genetic distances were quantified using pairwise $\mathrm{F}_{\mathrm{ST}}$ values

231 (Weir and Cockerham 1984) and the geographic distances as the linear distance in 232 kilometres (see the Supplementary Material S2).

233

234 Does marmots' response to alarm calls vary depending on the 235 population of origin of the emitter?

236 Between mid-May and mid-July, 2015, a playback experiment was carried out on 237 marmots from La Sassière and Tignes from 8:00 a.m. to 6:00 p.m. Each individual was 238 tested once with a call from Cerdanya, Sassière or Tignes. Forty-three tests were 239 performed in La Sassière (16, 17 and 10 tests with alarm calls from La Sassière, Tignes 240 and La Cerdanya respectively) and 34 tests were done in Tignes (12, 8 and 13 tests with 241 alarm calls from Tignes, La Sassière and La Cerdanya respectively). To limit 242 pseudoreplication, we picked up and broadcasted 7 recordings of calls (See previous 243 section "Does the acoustic structure of alarm calls differ between populations?") for 244 each of the three populations used. We chose signals with a high signal to noise ratio so 245 as the response observed cannot be due to eventual uniqueness of one soundtrack.

246 Moreover to avoid a neighbour-stranger effect we chose carefully the sound track used 247 for each test to ensure that it was recorded in another part of each population, away 248 from the tested marmot (at least 500m). To avoid habituation of the tested marmots due 249 to repetitions of trials over a short time, the same calling bout was never displayed more 250 than once to a given territory and two neighbouring territories were never tested 251 successively.

252 Each playback bout was composed of 5 alarm calls within 3 s, mimicking an 
253 average natural bout (measurement performed on 30 bouts recorded in our study). The

254 amplitude of alarm calls of Alpine marmots has not been measured accurately before

255 (i.e. the precise distance between the emitter and the sound level meter, taking the exact

256 position of the head of the marmot into account). Hence, we decided to match by ear the

257 amplitude of the calls used during our test to a natural call. Alarm calls were emitted at

$258100 \mathrm{~dB}(\mathrm{C})$ using a speaker (SMC8060 Beyma amplified loudspeaker) connected to a

259 Fostex FR2LE, measurement done with a Lutron SL-4001, C weighting, slow settings).

260 This amplitude is closed to the value measured on yellow-bellied marmot Marmota

261 flaviventris (95-100 dB (Lea and Blumstein 2011)).

262 The speaker was placed on the ground in the upper part of the focal territory

263 directed towards the main burrow entrance. Marmots typically retreated into their

264 burrows during the installation but they re-emerged within minutes. Once a marmot was

265 between $5 \mathrm{~m}$ and $10 \mathrm{~m}$ away from any burrow entrance and displayed a normal activity

266 such as foraging, an observer placed outside the focal family group triggered the alarm

267 call playback (beginning of the trial). At the same time, observers filmed the focal adult

268 individual of the focal family group with a digital video camera (Sony® Handycam

269 model DCR-DVD650 or JVC® digital video model GZ-E 209). The trial was

270 considered completed when the focal individual entered into a burrow, resumed a

271 normal activity (i.e., foraging) or 5 minutes after the beginning of the trial.

272 All video recordings were displayed in AVS Video Editor (version 7.1) in slow

273 motion (x0.25) by a unique observer, blind to playback treatment, to ensure an accurate

274 identification of behaviours as well as to record their duration with an accuracy of $0.01 \mathrm{~s}$.

275 In one case over 77 , more than a single animal was present, we thus conducted the

276 statistical analyses with and without this trial but given that the results were 
277 qualitatively identical and quantitatively similar, we chose to kept this experiment in the

278 analyses. We collected the occurrence (coded as a binary outcome) of vigilance,

279 flight/running, entrance into a burrow, time spent vigilant and time until the focal 280 individual resumed foraging. Vigilance behaviour was defined as any posture where

281 marmots were standing on their rear feet, or standing on their four feet but suddenly

282 putting their head up and maintaining it above the horizontal plane of their body.

283 Flight/running was defined as an escape-related behaviour towards a burrow entrance

284 and was considered to be a more extreme response than any vigilance posture, without 285 necessarily entering in the burrow.

286

287 Statistical analyses

288 To test whether the response to alarm calls depends on the origin of the signal, the 289 occurrence of flight and of the entry in a burrow were entered as response variables in 290 two generalized linear models (GLMs) with a logit link and the variance given by a 291 binomial distribution. Since in nearly all playback trials (72 over 77), individuals 292 became vigilant, the frequency of this behaviour could not be considered.

293 The time spent vigilant and the time before resuming a normal activity were further 294 entered as response variables in two other GLMs with a logarithmic link and the 295 variance given by a Gamma distribution. In the last model, we categorized the intensity 296 of the response of the focal individual in four categories: no response, vigilance only, 297 flight and entry in a burrow; and we entered this ordinal variable in an ordered logistic 298 regression model. In each of these five models, we first tested whether the responses 299 were different when the playback alarm call originated from the population of the focal 300 individual or from another population by entering the origin of the playback as a two- 
301 modalities factor (same or other population) in interaction with the population of the 302 focal individual (Tignes or Sassière) as explanatory variables. Second, we tested

303 whether the geographic distance between the focal individual and the signaller could 304 further impact the responses by entering the origin of the playback as a three-modalities 305 factor (same, close, far) in interaction with the population of the focal individual (Tignes 306 or Sassière) as explanatory variables. All analyses were performed using the R software 307 (Version 3.1.1) and packages 'nlme' (Pinheiro et al. 2018), 'multcomp' (Hothom et al. 308 2008), 'ade4' (Dray and Dufour 2007), 'MASS' (Venables and Ripley 2002).

\section{Results}

\section{Does the acoustic structure of alarm calls differ among populations?}

312 Marmot alarm calls from the four populations differed significantly in their initial 313 frequencies $\left(\mathrm{F}_{1,190}=4.75, P<0.01\right)$, ascendant phases' durations $\left(\mathrm{F}_{3,190}=11.58, P<\right.$ $3140.001)$, stationary phases' durations $\left(\mathrm{F}_{3,190}=9.57, P<0.001\right)$ but not in their descendant 315 phases' durations $\left(\mathrm{F}_{3,190}=2.45, P=0.07\right)$.

316 Despite a strong overlap among the four populations when compared altogether 317 (Supplementary Material S3), alarm calls were always assigned more often to the 318 population their emitter originated from than to any other population. Effectively, calls 319 were correctly classified in $41.96[35.71 ; 48.35] \%$ of the cases (while the percentage of 320 random classification would have been $25 \%$ ). When populations were compared two by

321 two, alarm calls were once again always better attributed to the population their emitters 322 originated from than to the other one (percentage of random classification: $50 \%$ ). 323 Percentages of correct classification ranged from 62.49 [54.17;69.79] $\%$ to 71.64 $324[63.70 ; 79.41] \%$ when comparing Tignes with Ripollès and Tignes with Cerdanya 
325 respectively (Table 2). All the acoustical variables (initial frequencies, ascendant, 326 stationary and descendant phases' durations) contributed to the discrimination among 327 the populations, but they seemed contribute differently to the differentiation between 328 each pair of populations (Fig. 2).

329 The acoustic distances between two populations was neither explained by their 330 genetic distance (Spearman $=-0.77, \mathrm{~N}=6, \mathrm{p}=0.92$ ) nor by their geographic distance 331 (Spearman $=-0.71, \mathrm{~N}=6, \mathrm{p}=1.00$ ). Moreover, there is no evidence of genetic isolation 332 by distance in our four populations (i.e. the genetic distances and the geographic 333 distances were not correlated, spearman's Rho $=0.43, \mathrm{~N}=6, \mathrm{p}=0.17$ ).

335 Does marmots' response to alarm calls vary depending on the 336 population of origin of the emitter?

337 Marmots exhibited lower intensity responses to an alarm call from their own population 338 than to an alarm call from another population $(\beta=-1.23 \pm 0.52, \mathrm{z}=-2.40, \mathrm{~N}=76, \mathrm{p}=$ 339 0.02). The odds of a marmot showing a higher response decreased by a factor of 0.29 $340[0.10 ; 0.78]$ when the alarm call originated from its own population compared to 341 another one. More specifically, marmots showed a significantly lower propensity to flee $342(\beta=-1.45 \pm 0.58, \mathrm{z}=-2.50, \mathrm{~N}=76, \mathrm{p}=0.01$, fig. $3-\mathrm{a})$ when the alarm call originated 343 from their own population than from nearby versus geographically remote population.

344 Although the rest of our results were not significant, marmots tended to be less likely to 345 enter their burrow $(7.14 \pm 1.86 \%$ vs. $16.67+6.67 \%, \beta=-0.96 \pm 0.83, \mathrm{z}=-1.15, \mathrm{~N}=76$, $346 \mathrm{p}=0.25$, fig. $3-\mathrm{b})$, to remain vigilant for a shorter time $($ median $=23.37 \mathrm{~s} v \mathrm{~s} .34 .58 \mathrm{~s}, \beta=$ $3470.002 \pm 0.006, \mathrm{z}=0.40, \mathrm{~N}=74, \mathrm{p}=0.68$, fig. 3 -c), and to resume a normal activity 348 more rapidly (median $=24.88 \mathrm{~s} v s .39 .35 \mathrm{~s}, \beta=0.003 \pm 0.005, \mathrm{z}=0.49, \mathrm{~N}=68, \mathrm{p}=0.62$, 
349 fig. 3-d) when the alarm call originated from their own population. The intensity of the 350 response was similar for alarm calls produced in a nearby or in a geographically distant

351 population (odds ratio $=0.73[0.19,2.64], \beta=-0.31 \pm 0.66, \mathrm{z}=-0.47, \mathrm{~N}=76, \mathrm{p}=0.64$ ).

352 The propensity to flee $(\beta=-0.20 \pm 0.83, \mathrm{z}=-0.24, \mathrm{~N}=76, \mathrm{p}=0.81$, fig. 3 -a), to enter in 353 a burrow (near: $88.00+2.64 \%$ vs. far: $78.26+3.91 \%, \beta=-0.71 \pm 0.80, \mathrm{z}=-0.89, \mathrm{~N}=$ $35476, p=0.37$, fig. $3-b)$, the amount of time spent vigilant (near $=34.58 \mathrm{~s} v s$. far $=31.9 \mathrm{~s}, \beta$ $355=-0.02 \pm 0.33, \mathrm{z}=-0.06, \mathrm{~N}=74, \mathrm{p}=0.95$, fig. 3 -c) and elapsed time before resuming a 356 normal activity (near $=38.16 \mathrm{~s} v s$. far $=39.35 \mathrm{~s}, \beta=-0.001 \pm 0.006, \mathrm{z}=-0.29, \mathrm{~N}=68, \mathrm{p}=$ 357 0.77, fig. 3-d) did not vary with the geographic distance between the focal and the other 358 population.

\section{Discussion}

361 In the present study we described for the first time the acoustic structure of alarm calls 362 produced by adult Alpine marmots in two native and two reintroduced wild populations.

363 We found that the acoustic structure of Alpine marmots alarm calls differed among the 364 four populations, which enabled us to assign calls described by four acoustic parameters 365 to their population of origin greater than by chance. Neither the genetic distance nor the 366 geographic distance explained the acoustic differences between populations. Finally, the 367 playback experiments provided evidence that receivers discriminate among alarm calls 368 from their own versus other populations. Surprisingly, intensity of marmots' responses 369 was lower when the playback calling bout originated from their own population than 370 when it came from another population. Again, these responses did not differ depending 371 on the genetic nor on the geographic distances. 
373 structure of Alpine marmots alarm calls differ among the four studied populations.

374 Indeed, using four acoustic parameters to describe each alarm call it was possible to

375 assign the signal to the population their emitters originated from with accuracy

376 exceeding that expected by chance. The presence of geographic markers in acoustic

377 signals have been shown repeatedly in bird songs (Nottebohm 1969; Mundinger 1982;

378 Zimmermann et al. 2016). The richness of avian vocal repertories offer a wide range of

379 possibilities for differentiation of geographic markers: changes in note combinations,

380 presence or absence of some notes (particularly during new population finding) and/or

381 rhythm of emission of different notes (Baker and Jenkins 1987; Handford 1988; Shieh

382 et al. 2013). Nevertheless, such markers have also been found within single stereotyped

383 acoustic elements, e.g. those produced by bottlenose dolphins, Tursiops spp. (Campbell

384 2004). Similarly to Campbell's (2004) study, we found that the general shape of

385 acoustic elements, as short as $0.2 \mathrm{~s}$, differed among marmot populations.

386 We further found a clear difference in the shape of alarm calls used by two

387 populations originating from two mountain ranges but also between populations

388 separated by only $5 \mathrm{~km}$ (i.e., Sassière and Tignes). Acoustic divergence is well 389 documented at a large spatial scale (Lougheed and Handford 1992; Wilczynski and 390 Ryan 1999). For instance, Shizuka et al. (2016) reported the existence of 13 discrete 391 song types in golden-crowned sparrows (Zonotrichia atricapilla) over 3,100 km in 392 Alaska. But, geographic variations in acoustic signals can also be observed at a 393 microgeographic scale. Leader et al. (2008) documented dialects in orange-tufted 394 sunbird (Nectarinia osea) within two sub-populations separated by a sharp boundary but 395 only $100 \mathrm{~m}$ apart from each other. Studies conducted at these different geographic scales 396 still remain scarce in mammals. At least two studies working on a phylogenetically 
397 close species to the Alpine marmot, the Gunnison's prairie dog (Cynomys gunnisoni), 398 have documented large or microgeographic differences in acoustic signals 399 (Slobodchikoff et al. 1998; Perla and Slobodchikoff 2002).

400 Genetic distance has been repeatedly hypothesized to explain acoustic 401 differences among populations (Wilczynski and Ryan 1999). However, in the present 402 study, we did not find any correlation between the acoustic and the geographic distances 403 or between the genetic and the acoustic distances. The peculiar status of our studied 404 populations is unlikely to explain such a lack of relationship: the two reintroduced 405 Pyrenean populations originated from Alpine populations that were farther away both 406 geographically and genetically than the two Alpine populations considered here (Bichet 407 et al. 2016). While Balaban (1988) found a correlation between signal characteristics 408 and genetic distance in two populations of swamp sparrow (Melopsiza georgiana), a 409 lack of congruence in divergence of acoustic signal and genetic characteristics has been 410 repeatedly observed in birds (Hafner and Petersen 1985; Payne and Westneat 1988;

411 Wright and Wilkinson 2001).

412 Four main hypotheses (i.e., learning, morphology and body mass differences, 413 antipredator strategies and local adaptation) have been proposed to explain the 414 occurrence of dialects. The learning hypothesis attributes acoustic differences among 415 populations to the colonization of a new area by young individuals before they have 416 learned the song structure from their parents (Thielcke 2008). Baker and Jenkins (1987) 417 invoked this cultural bottleneck to explain the presence of dialects in isolated 418 populations of chaffinches. However, an interspecific cross-fostering experiment with 419 ground squirrels failed to provide evidence for the learning hypothesis (Matocha 1975). 420 Although the failure to learn allospecific calls does not preclude learning the nuances of 
421 conspecific calls, the learning process is probably not very important in marmots.

422 Moreover, the founders caught for the reintroduction events in Pyrenees were all adults.

423 For all these reasons, the learning hypothesis is unlikely to explain geographic variation

424 in the acoustic structure of alarm calls found in our study.

425 Among other factors that could lead to geographic variation, indirect selective 426 pressures on acoustic signals may alter vocalization characteristics (Podos 2001). In

427 Alpine marmot, mechanistic processes may cause the alarm call divergence. For 428 instance, significant differences in both morphology and body mass between two 429 (Sassière and Cerdanya) of the four studied populations have been found (Ferrandiz430 Rovira et al, in prep). Mechanical links between morphology and acoustic signals exist 431 in many groups (e.g. in anurans (Hoskin et al 2009; Lengagne 2017), in birds (Nowicki 432 1987; Fletcher and Tarnopolski 1990)). For example, a study conducted on Darwin's 433 finches showed that the adaptive evolution of beaks for feeding also influences the 434 acoustic structure of their songs (Podos 2001). Although less investigated, such link has 435 also been found for alarm calls in the speckled ground squirrel (Spermophilus suslicus, 436 Matrosova et al. 2012). Nevertheless, further studies are needed to firmly establish a 437 direct link between morphology and alarm call structure.

438 Antipredator strategies such as the use of alarm call is also known to strongly 439 interact with predator dangerousness and predation risk (Dutour et al. 2016,2017). 440 Indeed, signal characteristics will differ according to predator characteristics 441 (Zuberbülher, 2009). For instance, mustached tamarins (Saguinus mystax) produce 442 different alarm calls for aerial versus terrestrial predators (Kirchhof and 443 Hammerschmidt 2006) or for the level of perceived threat (Coss et al. 2007). In the 444 present study, this is unlikely to explain the observed marmots' geographic variation 
445 because alarm calls have been elicited by a human approach at the same distance from 446 burrows $(60-80 \mathrm{~m})$ and hunting was forbidden in the different marmot populations.

447 In agreement with the local adaptation hypothesis, dialects could also result

448 from the optimization of sound transmission within local environment along various

449 transmission channel (Morton 1975). Signal alteration depends on vegetation cover

450 density, atmospheric turbulence, or height above the ground at which a signal is

451 transmitted (Wiley and Richards 1978; Lengagne et al. 1999). Moreover, information

452 transfer efficiency is linked to the intensity and the quality of the background noise

453 (Ryan and Brenowitz 1985; Lengagne and Slater 2002). In birds, a study on dialect

454 suggested that call structure have been shaped by local propagation conditions

455 (Doutrelant et al. 1998) and another study with Gunnison's prairie dog emphasized a

456 link between alarm call structure and habitat characteristics: geographic variant calls

457 resulted in significant differences in transmission performance through different

458 environments (Perla and Slobodchikoff 2002). Nevertheless, in our case, although we

459 did not measure vegetation coverage, the predominant vegetation formation consisted in

460 high altitude alpine meadows which should be quite similar from a population to

461 another. Vegetation is thus unlikely to affect alarm call propagation here. Hence, a

462 minimal effect of the propagation conditions on the evolution of alarm call structure in

463 the four studied populations is expected in agreement with previous studies on marmots

464 conducted by Daniel and Blumstein (1998). Background noise level, one major

465 component of the transmission channel also influence signal evolution. One way to 466 improve signal efficiency in such case is to avoid overlapping with low frequency 467 corresponding to background noise and thus to modify signal spectrum towards high 468 pitched frequencies. Anthropogenic effects on alarm calls had already been 
469 hypothesized to explain differences in alarm calls' dialects of speckled ground squirrels

470 (Matrosova et al. 2016). We observed important noise differences among the studied

471 populations. The "Tignes" population is located in a mountain resort and could be

472 considered as disturbed by anthropogenic noises (traffic, helicopter...). However, we

473 did not observe higher, minimum or maximum frequencies in the alarm calls recorded

474 in Tignes compared to the other studied populations for which there was no evidence of 475 environmental noise.

476 In addition to direct or indirect selection processes we cannot preclude the fact

477 that acoustic differences observed among populations were due to a random process.

478 Consistent with this explanation, we found that multiple sets of acoustical variables

479 stoodd out to discriminate between each pair of populations. This lack of consistency

480 suggests that evolution of alarm call characteristics may not be explained by a unique

481 selective process.

482 As fleeing in response to alarm calls should provide a selective advantage by

483 increasing survival, one predicts that marmots should react to all alarm calls despite

484 discrimination abilities (but see trade-off between vigilance and foraging, Lima and Dill

485 1990). Surprisingly, our tests revealed that receivers perceived acoustic differences and

486 categorized alarm calls as local or non-local calls. Such behavioural consequences

487 imply that these acoustic differences are meaningful for them (Soha et al. 2016). Most

488 studies focused on male territorial defence or female attraction in birds and their results

489 are contrasted with stronger response to local songs in some cases, absence of

490 preferences or mixed responses in others (see Becker 1983; Catchpole and Slater 2008).

491 In an alarm context, experimental approaches with playbacks emphasized that intensity

492 of animal response varies according to the past reliability of the signaller (Cheney and 
493 Seyfarth 1988)) or to the familiarity of the members of the colony (Hare and Warkentin

494 2012). Nevertheless, no study has been conducted so far to determine whether animals

495 discriminate and react differently to conspecific alarm calls according to its population

496 (i.e. geographical origin). Our results thus show for the first time that animals

497 discriminate among calls recorded in different populations and react accordingly. We

498 expected that a divergence in the alarm signal induce an alteration of alarm information

499 and, according to Hanson and Coss (2001), we expected a reduced behavioural response

500 to alarm calls of non-local congeners in tested animals. Surprisingly, behavioural

501 responses obtained after playback of alarm calls from different populations showed the

502 reverse. Indeed, animals reacted more strongly to playback of alarm calls originating

503 from foreign populations. Moreover, the intensity of the response was similar for alarm

504 calls produced in a nearby or in a geographically distant population suggesting that

505 these signals represent an equally threatening situation for animals. Our results may be

506 explained by a difference in the predator pressure or predator strategy (Dutour et al.

507 2016). Even though we did not measure predator pressure precisely, the two main

508 predators of marmots, the golden eagle (Aquila chrysaetos) and the red fox (Vulpes

509 vulpes), were present in the four studied population. Hence, predator pressure is

510 unlikely to explain differences observed in marmot responses to playback. Previous

511 experiments on rodents showed that they discriminate alarm calls from neighbours (i.e.

512 familiar) versus unfamiliar individuals. In the present study, marmots displayed a

513 stronger response to alarm calls originating from foreign populations compared to their

514 native one. Nevertheless, this familiar versus unfamiliar discrimination process cannot

515 explain our results because all animals were tested with unknown signals even when

516 they were tested with calls of their own population. Our results may be explained by the 
517 fact that marmots estimate the information reliability received and reacted accordingly.

518 Blumstein et al. (2004) observed a stronger response to unreliable than reliable alarm

519 calls in yellow-bellied-marmot (Marmota flaviventris) and suggests that such difference

520 was due to the fact that a marmot hearing an unreliable alarm call makes its own

521 independent assessment of relative risk and thus invests more in antipredator behaviour

522 (but see opposite results in Richardson's ground squirrels Spermophilus richardsonii:

523 Hare and Atkins 2001).

524 The presence of geographic markers in acoustic signals involved in a context of 525 mate choice and intra-sexual competition have been repeatedly found in avian species

526 (Nottebohm 1969; Mundinger 1982; Zimmrmann et al. 2016). Both random and

527 selective processes linked to sexual selection that may act via genetic or cultural 528 transmission pathways could explain their origin. In the context of alarm, further 529 research on the proximate causes of geographical markers as well as on the relationship 530 between geographical markers, reliability of the signal and behavioural responses are 531 now required to better understand how predation pressure and natural selection could 532 drive the evolution of communication.

\section{Electronic supplementary material}

535 The online version of this article contains supplementary material, which is available to 536 authorized users. 


\section{REFERENCES}

538 Baker M (1982) Genetic population structure and vocal dialects in Zonotrichia

539 (Emberizidae). In: Acoustic communication in birds, p. 209-235. New York: Academic 540 Press.

541 Baker MC, Cunningham MA (1985) The biology of bird-song dialects. Behav Brain Sci $5428: 85$

543 Baker AJ, Jenkins PF (1987) Founder effect and cultural evolution of songs in an 544 isolated population of chaffinches, Fringilla coelebs, in the Chatham Islands. Anim 545 Behav 35:1793-1803

546 Balaban E (1988) Bird song syntax: learned intraspecific variation is meaningful. Proc

547 Natl Acad Sci USA 85:3657-60

548 Becker PH (1983) The coding of species-specific characteristics in bird sounds. In:

549 Kroodsma D, Miller E (eds) Acoustic communication in birds , New York: Academic 550 press, New York pp 213-252.

551 Bichet C, Sauzet S, Averty L, Dupont P, Ferrandiz-Rovira M, Ferrari C,Figueroa I, 552 Tafani M, Rézouki C, López BC, Cohas, A (2016) Multiple geographic origins and high 553 genetic differentiation of the Alpine marmots reintroduced in the Pyrenees. Conserv 554 Genet 17:1157-1169 (DOI: 10.1007/s10592-016-0851-4).

555 Blumstein DT, Armitage KB (1997) Alarm calling in yellow-bellied marmots: I. The 556 meaning of situationally variable alarm calls. Anim Behav 53:143-171

557 Blumstein DT, Verenyre L, Daniel JC (2004) Reliability and the adaptive utility of 558 iscrimination among alarm callers. Proc R Soc B 271:1851-1857

559 Blumstein DT, Munos O (2005) Individual, age and sex-specific information is

560 contained in yellow-bellied marmot alarm calls. Anim Behav 69:353-361 
561 Blumstein DT (2007) The evolution, function, and meaning of marmot alarm

562 communication. Adv Study Behav 37:371-400

563 Blumstein DT, Nguyen KT, Martin JGA (2013) Ontogenetic variation of heritability and

564 maternal effects in yellow-bellied marmot alarm calls. Proc R Soc B 280:20130176

565 Boul KE, Funk WC, Darst CR, Cannatella DC, Ryan MJ (2007) Sexual selection drives

566 speciation in an Amazonian frog. Proc R Soc B 274:399-406

567 Bradley DW, Molles LE, Waas JR (2013) Local-foreign dialect discrimination and

568 responses to mixed-dialect duets in the North Island kōkako. Behav Ecol 24:570-578

569 Campbell GS (2004) Quantitative comparison of bottlenose dolphin (Tursiops spp.)

570 whistles from three geographic regions. MS thesis.

571 Campbell P, Pasch B, Pino JL, Crino OL, Phillips M, Phelps SM (2010) Geographic

572 variation in the songs of neotropical singing mice: testing the relative importance of

573 drift and local adaptation. Evolution 64:1955-1972

574 Catchpole C, Slater P (2008) Bird song. Cambridge: Cambridge university press.

575 Charrier I, Mathevon N, Aubin T (2013) Bearded seal males perceive geographic

576 variation in their trills. Behav Ecol Sociobiol 67:1679-1689

577 Cheney DL, Seyfarth RM (1988) Assessment of meaning and the detection of unreliable

578 signals by vervet monkeys. Anim Behav 36:477-486

579 Cleator HJ, Stirling I, Smith TG (1989) Underwater vocalizations of the bearded seal

580 (Erignathus barbatus). Can J Zool 67:1900-1910

581 Colbeck GJ, Sillett TS, Webster MS (2010. Asymmetric discrimination of geographical 582 variation in song in a migratory passerine. Anim Behav 80:311-318

583 Conner DA (1982) Dialects versus geographic variation in mammalian vocalizations.

584 Anim Behav 30:297-298 
585 Coss RG, McCowan B, Ramakrishnan U (2007) Threat- related acoustical differences

586 in alarm calls by wild bonnet macaques (Macaca radiata) elicited by python and

587 leopard models. Ethology 113:352-367.

588 Couturier M (1955) Acclimatation et acclimatement de la Marmotte des Alpes,

589 Marmota marmota (Linné 1758), dans les Pyrénées françaises. Saugetierkundliche

590 Mitteilungen 3:105-108

591 Daniel JC, Blumstein DT (1998) A test of the acoustic adaptation hypothesis in four

592 species of marmots. Anim Behav 56:1517-1528

593 Danner JE, Danner RM, Bonier F, Martin PR, Small TW, Moore IT (2011) Female, but

594 not male, tropical sparrows respond more strongly to the local song dialect: implications

595 for population divergence. Am Nat 178:53-63

596 Davidson SM, Wilkinson GS (2002) Geographic and individual variation in

597 vocalizations by male Saccopteryx bilineata (Chiroptera: Emballonuridae). J Mammal

$598 \quad 83: 526-535$

599 Dray S, Dufour AB (2007) The ade4 package: implementing the duality diagram for 600 ecologists. J Stat Softw 22:1-20

601 Doutrelant C, Aubin T, Hittier S, Lambrechts MM (1998) Two distinct song populations

602 of blue tit Parus caeruleus in the French mediterranean. Bioacoustics 9:1-16

603 Dutour M, Lena JP, Lengagne T (2016) Mobbing behaviour varies according to predator

604 dangerousness and occurrence. Anim Behav 119:119-124

605 Dutour M, Lena JP, Lengagne T (2017) Mobbing behaviour in a passerine community

606 increases with prevalence in predator diet. Ibis 159:324-330

607 Fletcher NH, Tarnopolsky A (1999) Acoustics of the avian vocal tract. J Acoust Soc Am $608 \quad 105: 35$ 
609 Francescoli G (2002) Geographic variation in vocal signals of Ctenomys pearsoni. Acta

610 Theriologica 47:35-44

611 Gray DA (2005) Does courtship behavior contribute to species-level reproductive

612 isolation in field crickets? Behav Ecol 16:201-206

613 Hafner DJ, Petersen KE (1985) Song dialects and gene flow in the white-crowned

614 sparrow, Zonotrichia leucophrys nuttalli. Evolution 39:687-694

615 Halfwerk W, Slabbekoorn H (2009) A behavioural mechanism explaining noise-

616 dependent frequency use in urban birdsong. Anim Behav 78:1301-1307

617 Handford P (1988) Trill rate dialects in the Rufous-collared Sparrow, Zonotrichia

618 capensis, in northwestern Argentina. Can J Zool 66:2658-2670

619 Hanson MT, Coss RG (2001) Age differences in the response of California ground 620 squirrels (Spermophilus beecheyi) to conspecific alarm calls. Ethology 107:259-275

621 Hare JF, Warkentin KJ (2012) The song remains the same: Juvenile Richardson's 622 ground squirrels do not respond differentially to mother's or colony member's alarm 623 calls. Curr Zool 58:773-780

624 Hare JF, Atkins BA (2001) The squirrel that cried wolf: reliability detection by juvenile 625 Richardson's ground squirrels (Spermophilus richardsonii). Behav Ecol Sociobiol $626 \quad 51: 108-112$

627 Hoskin CJ, James S, Grigg GC (2009) Ecology and taxonomy-driven deviations in the 628 frog call-body size relationship across the diverse Australian frog fauna. J Zool 278:3662941

630 Hothorn T, Bretz F, Westfall P (2008) Simultaneous inference in general parametric 631 models. Biometrical J 50:346-363

632 Hunter M, Krebs J (1979) Geographical variation in the song of the great tit (Parus 
633 major) in relation to ecological factors. J Anim Ecol 48:759-785

634 Janik V, Slater P (2003) Traditions in mammalian and avian vocal communication. In:

635 Fragaszy MD, Perry MD (eds) The biology of tradition: models and evidences. ,

636 Cambridge University Press, Cambridge, pp 213-235.

637 Kirchhof J, Hammerschmidt K (2006) Functionally referential alarm calls in tamarins

638 (Saguinus fuscicollis and Saguinus mystax) evidence from playback experiments.

639 Ethology 112:346-354

640 Krebs J, Kroodsma D (1980) Repertoires and geographical variation in bird song. Adv

641 Study Behav 11:143-177

642 Kroodsma D (2004) The diversity and plasticity of birdsong. In: Marler P, Slabbekoorn

643 H (eds) Nature's Music . London: Elsevier Academic, London, pp 108-130

644 Lameira AR, Delgado RA, Wich SA (2010) Review of geographic variation in terrestrial

645 mammalian acoustic signals: Human speech variation in a comparative perspective. J

646 Evol Psychol 8:309-332

647 Lea AJ, Blumstein DT (2011) Age and sex influence marmot antipredator behavior

648 during periods of heightened risk. Behav Ecol Sociobiol 65:1525-1533

649 Leader N, Wright J, Yom-Tov Y (2002) Dialect discrimination by male Orange-Tufted

650 sunbirds (Nectarinia osea): reactions to own vs. neighbor dialects. Ethology 108:367-

651376

652 Leader N, Geffen E, Mokady O, Yom-Tov Y (2008) Song dialects do not restrict gene

653 flow in an urban population of the orange-tufted sunbird, Nectarinia osea. Behav Ecol

654 Sociobiol 62:1299-1305

655 Lengagne T, Aubin T, Jouventin P, Lauga J (1999) Acoustic communication in a king 656 penguin colony: importance of bird location within the colony and of the body position 
657 of the listener. Polar Biol 21:262-268

658 Lengagne T, Slater PJB (2002) The effects of rain on acoustic communication: tawny

659 owls have good reason for calling less in wet weather. Proc R Soc B 269:2121-5

660 Lengagne T, Voituron Y, Gomez D (2017) Male within-individual variability in a sexual

661 signal component and its impact on female choice. Behav Ecol 28:108-116

662 Lima SL, Dill LM (1990) Behavioral decisions made under the risk of predation: a

663 review and prospectus. Can J Zool 68:619-640

664 Lin A, Liu H, Chang Y, Lu G, Feng J (2016) Behavioural response of the greater

665 horseshoe bat to geographical variation in echolocation calls. Behav Ecol Sociobiol

$66670: 1765-1776$

667 Lougheed SC, Handford P (1992) Vocal dialects and the structure of geographic

668 variation in morphological and allozymic characters in the rufous- collared sparrow,

669 Zonotrichia capensis. Evolution 46:1443-1456

670 Maeda T, Masataka N (2010) Locale-specific vocal behaviour of the tamarin (Saguinus

671 I. labiatus). Ethology 75:25-30

672 Manser MB (2001) The acoustic structure of suricates' alarm calls varies with predator

673 type and the level of response urgency. Proc R Soc B 268:2315-2324

674 Matocha K (1975) Vocal communication in ground squirrels, genus Spermophilus. PhD

675 Thesis. Texas Tech University.

676 Matrosova VA, Volodin IA, Volodina EV, Babitsky AF (2007) Pups crying bass: vocal

677 adaptation for avoidance of age-dependent predation risk in ground squirrels? Behav

678 Ecol Sociobiol 62:181-191.

679 Matrosova VA, Pivanova S V., Savinetskaya LE, Volodin IA, Volodina EV, Shekarova

680 ON (2012) The between-population variation of the alarm call in the speckled ground 
681 squirrel (Spermophilus suslicus, Rodentia, Sciuridae): effects of sex, age and body 682 mass. Zool Zhurnal 91:453-463

683 Matrosova VA, Rusin MY, Volodina EV, Proyavka SV, Savinetskaya LE, Shekarova 684 ON, Rashevska HV, Volodin IA (2016) Genetic and alarm call diversity across scattered 685 populations of speckled ground squirrels (Spermophilus suslicus). Mamm Biol 81:255686265

687 Mortega KG, Flinks H, Helm B (2014) Behavioural response of a migratory songbird to 688 geographic variation in song and morphology. Front Zool 11:85

689 Morton ES (1975) Ecological sources of selection on avian sounds. Am Nat 109:17-34

690 Mundinger P (1982) Microgeographic and macrogeographic variation in the acquired 691 vocalizations of birds. In: Kroodsma D, Miller E (eds) Acoustic communication in birds 692 New York: Academic Press, New York, pp 147-208

693 Nicholls JA, Goldizen AW (2006) Habitat type and density influence vocal signal 694 design in satin bowerbirds. J Anim Ecol 75:549-558

695 Nicholls JA (2008) Site specificity in advertisement calls and responses to playbacks of 696 local and foreign call variants in satin bowerbirds, Ptilonorhynchus violaceus. Behav 697 Ecol Sociobiol 62:831-841

698 Nottebohm F (1969) The song of the chingolo, Zonotrichia capensis, in Argentina: 699 description and evaluation of a system of dialects. Condor 71:299-315

700 Nowicki S (1987) Vocal tract resonances in oscine bird sound production: evidence 701 from birdsongs in a helium atmosphere. Nature 325:53-55

702 Oksanen J, Blanchet FG, Friendly M, Kindt R, Legendre P, McGlinn D, Minchin PR, 703 O'Hara RB, Simpson GL, Solymos P, Stevens MHH, Szoecs E, Wagner H (2018) Vegan 704 R package version 2.5-2. Community Ecology Package. 
705 Parmentier E, Lagardère J, Vandewalle P, Fine M (2005) Geographical variation in 706 sound production in the anemonefish Amphiprion akallopisos. Proc R Soc B 272:1697$707 \quad 1703$

708 Payne RB, Westneat DF (1988) A genetic and behavioral analysis of mate choice and 709 song neighborhoods in indigo buntings. Evolution 42:935-947

710 Perla BS, Slobodchikoff CN (2002) Habitat structure and alarm call dialects in

711 Gunnison's prairie dog (Cynomys gunnisoni). Behav Ecol 13:844-850

712 Perrin C, Allainé D, Leberre M (1993) Socio-spatial organization and activity 713 distribution of the Alpine marmot Marmota marmota - preliminary results. Ethology $714 \quad 93: 21-30$

715 Perry EA, Terhune JM (1999) Variation of harp seal (Pagophilus groenlandicus) 716 underwater vocalizations among three breeding locations. J Zool 249:181-186

717 Pinheiro J, Bates D, DebRoy S, Sarkar D (2018) nlme: Linear and Nonlinear Mixed 718 Effects Models.

719 Podos J (2001) Correlated evolution of morphology and vocal signal structure in 720 Darwin's finches. Nature 409:185-188

721 Podos J (2007) Discrimination of geographical song variants by Darwin's finches. Anim 722 Behav 73:833-844

723 Podos J, Warren PS (2007) The evolution of geographic variation in birdsong. Adv 724 Study Behav 37:403-458

725 Price T (2008) Speciation in birds. Greenwood: Roberts and Company Publishers.

726 Ramousse R, Martinot JP, Le Berre M (1992) Twenty years of re-introduction policy of 727 alpine marmots from the national park of La Vanoise (French Alps). In: Proceedings of 728 the 1st International Conference on Genus Marmota, p. 171-177. 
729 Randler C, Förschler MI (2011) Heterospecifics do not respond to subtle differences in

730 chaffinch mobbing calls: message is encoded in number of elements. Anim Behav

$731 \quad 82: 725-730$

732 Rendall D, Owren MJ, Ryan MJ (2009) What do animal signals mean? Anim Behav 78:

$733 \quad 233-240$

734 Ruegg K, Slabberkoorn H, Clegg S, Smith TB (2006) Divergence in mating signals 735 correlates with ecological variation in the migratory songbird, Swainson's thrush

736 (Catharus ustulatus). Mol Ecol 15:3147-3156

737 Ryan MJ, Brenowitz EA (1985) The role of body size phylogeny and ambient noise in

738 the evolution of bird song. Am Nat 126:87-100

739 Schlenker P, Chemla E, Arnold K, Lemasson A, Ouattara K, Keenan S, Stephan C, 740 Ryder R, Zuberbühler K (2014) Monkey semantics: two 'dialects' of Campbell's

741 monkey alarm calls. Linguist Philos. 37:439-501

742 Searcy WA, Nowicki S, Hughes M, Peters S (2002) Geographic song discrimination in

743 relation to dispersal distances in song sparrows. Am Nat 159:221-230

744 Shieh B-S, Liang S-H, Yuan H-W, Chen CC (2013) Experimental evidence that distinct 745 song phrases in the Grey-cheeked Fulvetta Alcippe morrisonia permit species and local 746 dialect recognition. Ibis 155:32-41

747 Shizuka D, Lein MR, Chilton G (2016) Range-wide patterns of geographic variation in 748 songs of Golden-crowned Sparrows (Zonotrichia atricapilla). Auk 133:520-529

749 Slabbekoorn H, Smith TB (2002) Bird song, ecology and speciation. Philos Trans R Soc 750 Lond B Biol Sci 357:493-503

751 Slater PJB (1986. The cultural transmission of bird song. Trends Ecol. Evol. 1:94-97.

752 Slobodchikoff CN, Ackers SH, Van Ert M. (1998) Geographic variation in alarm calls of 
753 Gunnison's prairie dogs. J Mammal 79:1265-1272

754 Soha JA, Poesel A, Nelson DA, Lohr B (2016) Non-salient geographic variation in

755 birdsong in a species that learns by improvisation. Ethology 122:343-353

756 Suzuki TN, Wheatcroft D, Griesser M (2016) Experimental evidence for compositional

757 syntax in bird calls. Nat Commun, 7:10986

758 Thielcke G (2008) On the origin of divergence of learned signals (songs) in isolated 759 populations. Ibis 115:511-516

760 Thomas JA, Puddicombe RA, George M, et al. (1988) Variations in underwater

761 vocalizations of Weddell seals (Leptonychotes weddelli) at the Vestfold Hills as a 762 measure of breeding population discreteness. In: Biology of the Vestfold Hills, 763 Antarctica. p. 279-284. Dordrecht: Springer Netherlands

764 Thomas J, Golladay C (1992) Geographic variation in leopard seal (Hydrurga leptonyx)

765 underwater vocalizations. In: Sensory systems of aquatic mammals. p. 201-221.

766 Woerden: De Spil Publishers.

767 Tubaro PL, Mahler B (1998) Acoustic frequencies and body mass in New World doves.

768 Condor 100:54-61

769 Uy JAC, Moyle RG, Filardi CE (2009) Plumage and song differences mediate species 770 recognition between incipient flycatcher species of the Solomon Islands. Evolution $771 \quad 63: 153-164$

772 Van Parijs S, Lydersen C, Kovacs K (2003) Vocalizations and movements suggest 773 alternative mating tactics in male bearded seals. Anim Behav 65:273-283

774 Velásquez N (2014) Geographic variation in acoustic communication in anurans and its 775 neuroethological implications. J Physiol 108:167-173

776 Venables WN, Ripley BD (2002) Modern Applied Statistics with S. Fourth Edition. 
777 New York: Springer.

778 Weir BS, Cockerham CC (1984) Estimating F-statistics for the analysis of population779 structure. Evolution 38:1358-1370

780 Wilczynski W, Ryan MJ (1999) Geographic variation in animal communication 781 systems. In: Foster SA, Endler JA (eds) Variation in behavior: perspectives on 782 evolutionary mechanisms. Oxford University Press, Oxford, pp 234-261.

783 Wiley HR, Richards DG (1982) Adaptations for acoustic communication in birds:

784 sound transmission and signal detection. In: Kroodsma D, Miller E (eds) Acoustic 785 Communication in Birds, New York: Academic Press, New York, pp 131-181

786 Wiley RH, Richards DG (1978) Physical constraints on acoustic communication in the 787 atmosphere: Implications for the evolution of animal vocalizations. Behav Ecol 788 Sociobiol 3:69-94

789 Wilkins MR, Seddon N, Safran RJ (2013) Evolutionary divergence in acoustic signals: 790 causes and consequences. Trends Ecol Evol 28:156-166

791 Wright TF, Wilkinson GS (2001) Population genetic structure and vocal dialects in an 792 amazon parrot. Proc R Soc B 268:609-16

793 Schlenker P, Chemla E, Arnold K, Lemasson A, Ouattara K, Keenan S, Stephan C, 794 Ryder R, Zuberbühler K (2014) Monkey semantics: two 'dialects' of Campbell's 795 monkey alarm calls. Linguist Philos 37:439-501

796 Wilczynski W, Ryan MJ (1999) Geographic variation in animal communication 797 systems. In: Foster SA, Endler JA (eds) Geographic variation in behavior: perspectives 798 on evolutionary mechanisms, Oxford University Press, Oxford, pp 234-261

799 Zimmerman HD, Ramsay SM, Mesias V, Mora M, Murray BW, Otter KA (2016) 800 Evolution of white-throated sparrow song: regional variation through shift in terminal 
801 strophe type and length. Behaviour 153:1839-1861

802 Zuberbühler K (2009) Survivor signals: the biology and psychology of animal alarm 803 calling. Adv Study Behav 40:277-322

804 Zuk M, Rotenberry JT, Simmons LW (2001) Geographical variation in calling song of 805 the field cricket Teleogryllus oceanicus: the importance of spatial scale. J Evol Biol $806 \quad 14: 731-741$ 


\section{FIGURE LEGENDS}

808 Fig. 1 Description of the acoustic structure of an Alpine marmot alarm call. (a)

809 Sonogram of a calling bout composed by two calls (FFT 1024pts, windows Hamming,

810 overlap 100\%). The colours represent the amplitude of the sound from blue (low

811 amplitude) to red (high amplitude). (b) Tracking of the fundamental frequency of an

812 alarm call by zero-crossing allowed us to measure three temporal parameters (in s):

813 duration of the ascendant phase (AD), stationary phase (SD) and descendant phase (DD)

814 and three frequency parameters (in Hz):initial (F1), maximum (F2) and final (F3)

815 frequencies.

817 Fig. 2 Linear Discriminant Analysis (LDA) on the ascendant (AD), stationary (SD) and

818 descendant (DD) phases' durations and the initial frequencies (F1) between each pair of

819 populations: Sassière versus Tignes (a); Cerdanya versus Ripollès (b); Sassière versus

820 Cerdanya (c); Sassière versus Ripollès (d); Tignes versus Cerdanya (e); and Tignes

821 versus Ripollès (f). The plots on the left part of the figure represent the first axis of the

822 LDA. The plots on the right part of the figure represent the contribution of the different

823 acoustical variables to the discrimination between the considered pair of populations.

825 Fig 3 Flee proportion (a), enter in burrow proportion (b), time spent vigilant (c) and

826 time before resuming normal activity (d) in relation to the distance between the 827 population of the receiver and the emitter (same, close - i.e. a geographically close 828 population being Sassière and Tignes - and remote - i.e. a geographically remote 829 population being Cerdanya). The black dots show the trials conducted in Sassière and 830 the white dots show the trials conducted at Tignes. The error bars represent standard 
831 errors. 


\section{TABLES AND TABLE LEGENDS}

833

834 Table 1 Pearson's correlation coefficients between acoustic features $(\mathrm{N}=894$ alarm

835 calls). *: $0.10<\mathrm{P}>0.05 ; * *: 0.05<\mathrm{P}>0.001 ; * * *: \mathrm{P}<0.001$

836

\begin{tabular}{llllll}
\hline & $\begin{array}{c}\text { Maximum } \\
\text { frequency }\end{array}$ & $\begin{array}{c}\text { Final } \\
\text { frequency }\end{array}$ & $\begin{array}{c}\text { Ascendant } \\
\text { phase }\end{array}$ & \multicolumn{1}{c}{ Stationary phase } & $\begin{array}{c}\text { Descendant } \\
\text { phase }\end{array}$ \\
\hline Initial frequency & $0.55^{* * *}$ & $0.67 * * *$ & $-0.17 * * *$ & $-0.02(\mathrm{P}=0.58)$ & $0.09^{* * *}$ \\
\hline Maximum frequency & & $0.74 * * *$ & $0.36^{* * *}$ & $0.08^{* *}$ & $0.30^{* * *}$ \\
\hline Final frequency & & & $0.09 * *$ & $0.07 *$ & $0.03(\mathrm{P}=0.36)$ \\
\hline Ascendant phase & & & $0.05(\mathrm{P}=0.11)$ & $0.30^{* * *}$
\end{tabular}


837 Table 2 Percentage of correct classification and acoustic structure (AD, SD, DD and F1) correlations with the Linear Discriminant Analysis (LDA) 838 canonical axis of the LDAs comparing each pair of studied populations. N: number of calls; AD: ascendant phases' durations; SD: stationary phases' 839 durations; DD: descendant phases' durations; F1: initial frequency.

\begin{tabular}{|c|c|c|c|c|c|c|}
\hline \multirow[t]{2}{*}{ Compared populations } & \multirow{2}{*}{$\begin{array}{c}\text { Mean correct } \\
\text { classification [95\% } \\
\text { CI] (\%) }\end{array}$} & \multicolumn{4}{|c|}{$\begin{array}{l}\text { Mean correlation }[95 \% \mathrm{CI}] \text { of acoustical structures with the first canonical axis of each } \\
\qquad \text { LDA }\end{array}$} & \multirow{2}{*}{$\begin{array}{c}\text { Pairwise } \\
\text { differences } \\
\text { in LD } \\
\text { functions } \\
\end{array}$} \\
\hline & & AD & SD & DD & F1 & \\
\hline $\begin{array}{l}\text { Sassière vs. Tignes } \\
(\mathrm{N}=137)\end{array}$ & $65.03[56.04 ; 73.63]$ & $0.35[0.30 ; 0.40]$ & $-0.51[-0.56 ;-0.47]$ & $0.77[0.73 ; 0.80]$ & $0.19[0.13 ; 0.25]$ & 44.45 \\
\hline $\begin{array}{l}\text { Cerdanya vs. Ripollès } \\
(\mathrm{N}=145)\end{array}$ & $65.13[56.25 ; 73.96]$ & $0.69[0.58 ; 0.78]$ & $0.61[0.48 ; 0.72]$ & $0.13[-0.04 ; 0.31]$ & $-0.24[-0.41 ;-0.07]$ & 42.21 \\
\hline $\begin{array}{l}\text { Sassière } v s . \text { Cerdanya } \\
(\mathrm{N}=137)\end{array}$ & $64.41[56.04 ; 72.53]$ & $0.63[0.51 ; 0.75]$ & $0.58[0.47 ; 0.68]$ & $-0.18[-0.35 ;-0.01]$ & $-0.65[-0.75 ;-0.54]$ & 41.10 \\
\hline $\begin{array}{l}\text { Sassière vs. Ripollès } \\
(\mathrm{N}=137)\end{array}$ & $62.95[54.95 ; 71.43]$ & $\begin{array}{l}0.04[-0.02 ; \\
0.09]\end{array}$ & $0.06[0.01 ; 0.12]$ & $-0.36[-0.41 ;-0.30]$ & $-0.52[-0.56 ;-0.47]$ & 43.08 \\
\hline $\begin{array}{l}\text { Tignes vs. Cerdanya } \\
(\mathrm{N}=153)\end{array}$ & 71.64 [63.70; 79.41] & $0.90[0.84 ; 0.95]$ & $0.13[-0.02 ; 0.28]$ & $0.50[0.38 ; 0.61]$ & $-0.47[-0.58 ;-0.35]$ & 41.85 \\
\hline $\begin{array}{l}\text { Tignes vs. Ripollès } \\
(\mathrm{N}=145)\end{array}$ & $62.49[54.17 ; 69.79]$ & $0.47[0.43 ; 0.51]$ & $-0.57[-0.61 ;-0.53]$ & $0.55[0.51 ; 0.59]$ & $-0.38[-0.43 ;-0.33]$ & 44.56 \\
\hline
\end{tabular}




\section{FIGURES}

842

843 Fig. 1
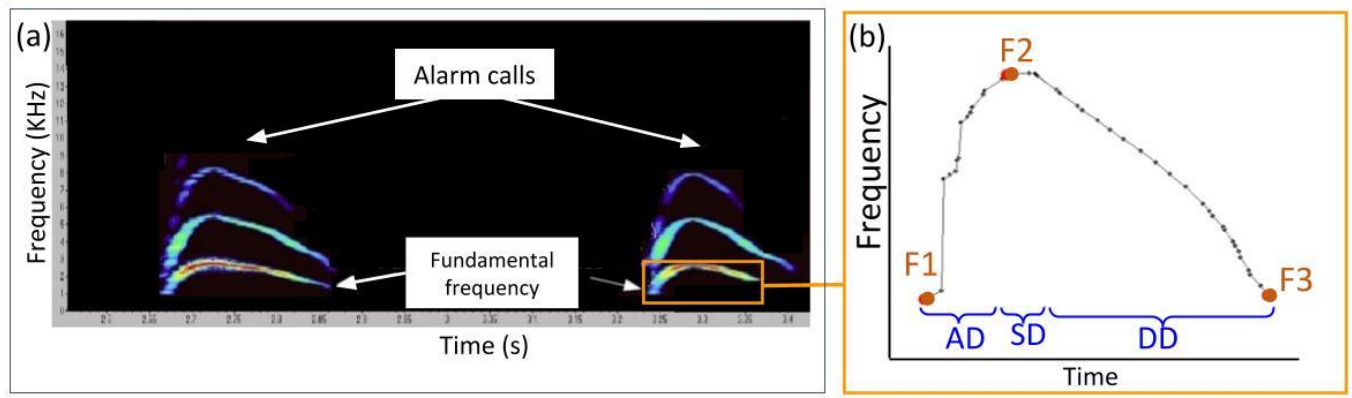

844 
845 Fig. 2
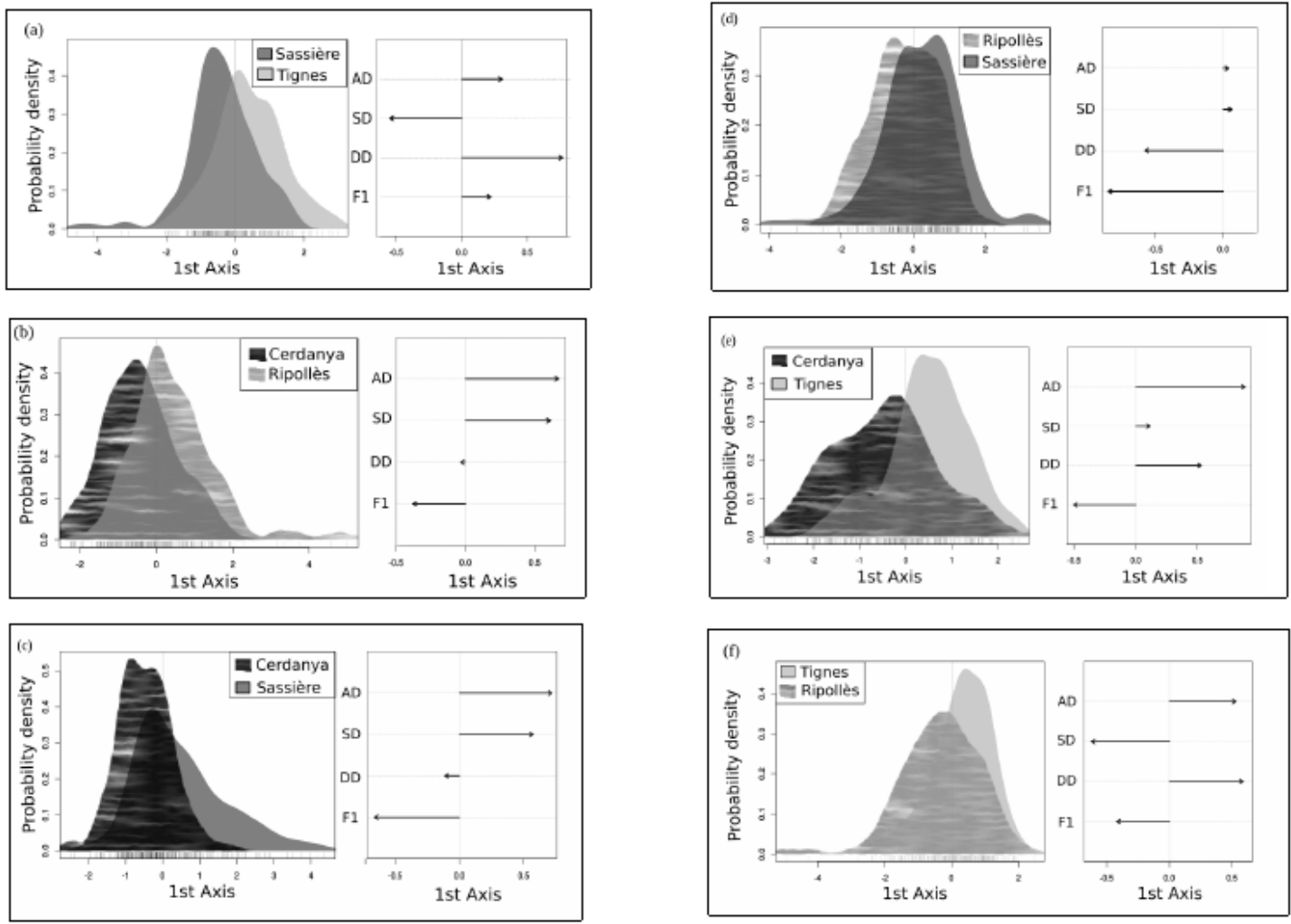

846 
$847 \quad$ Fig. 3

848
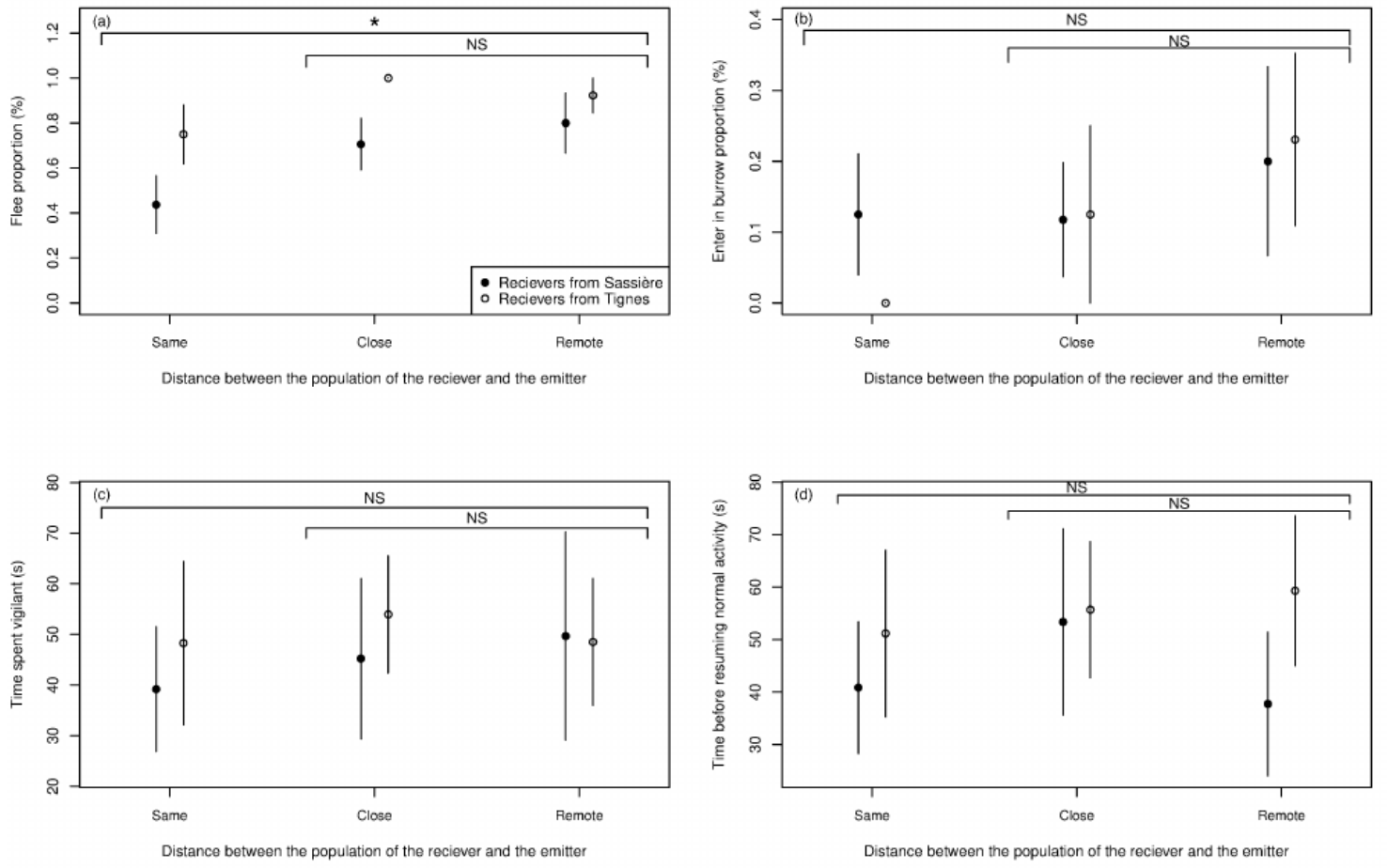

849

850 

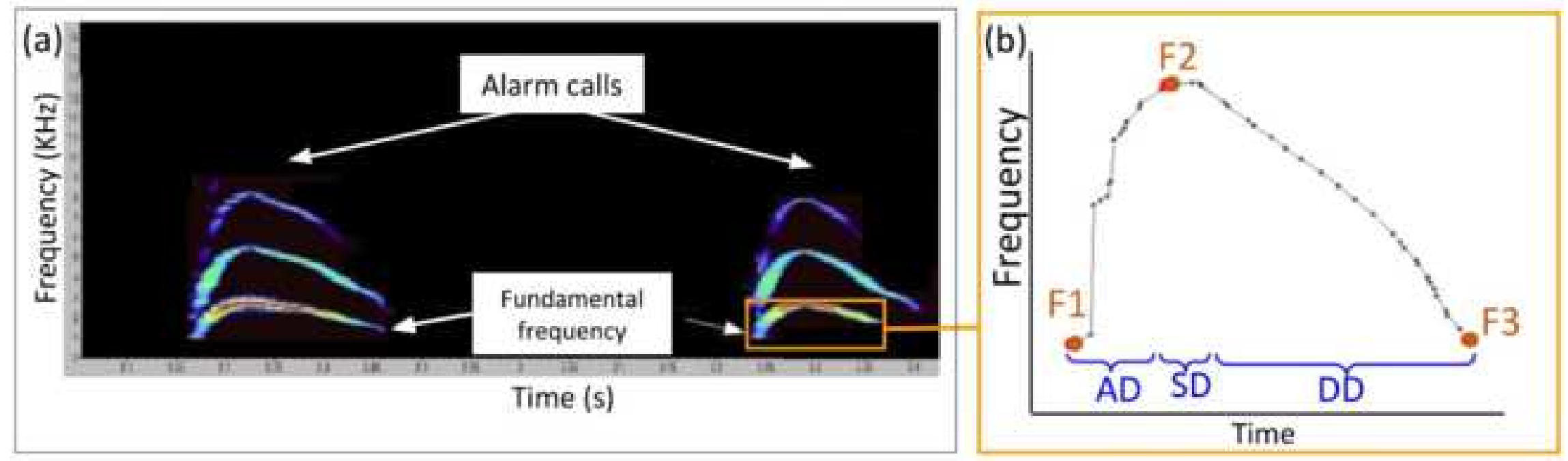

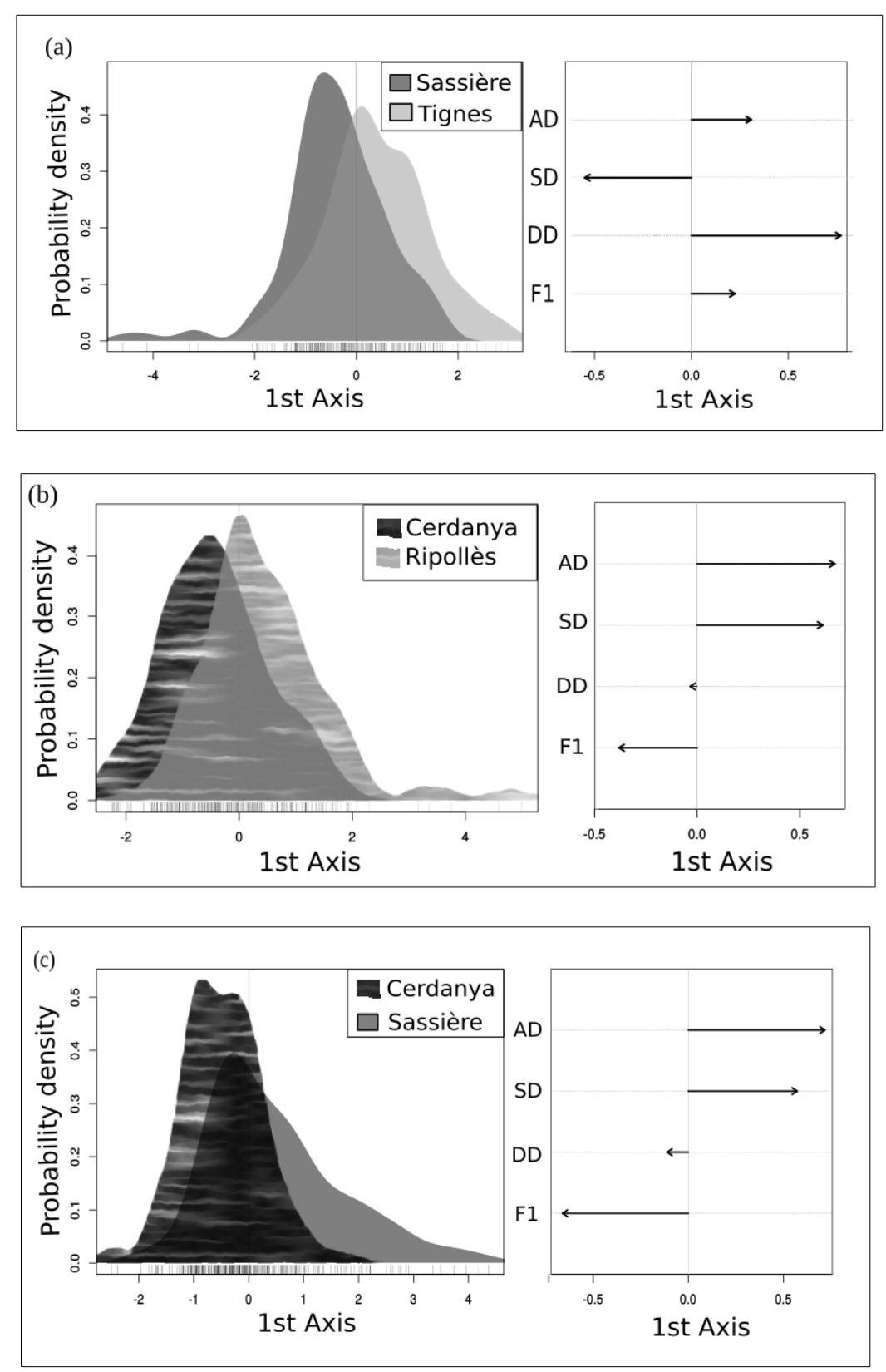
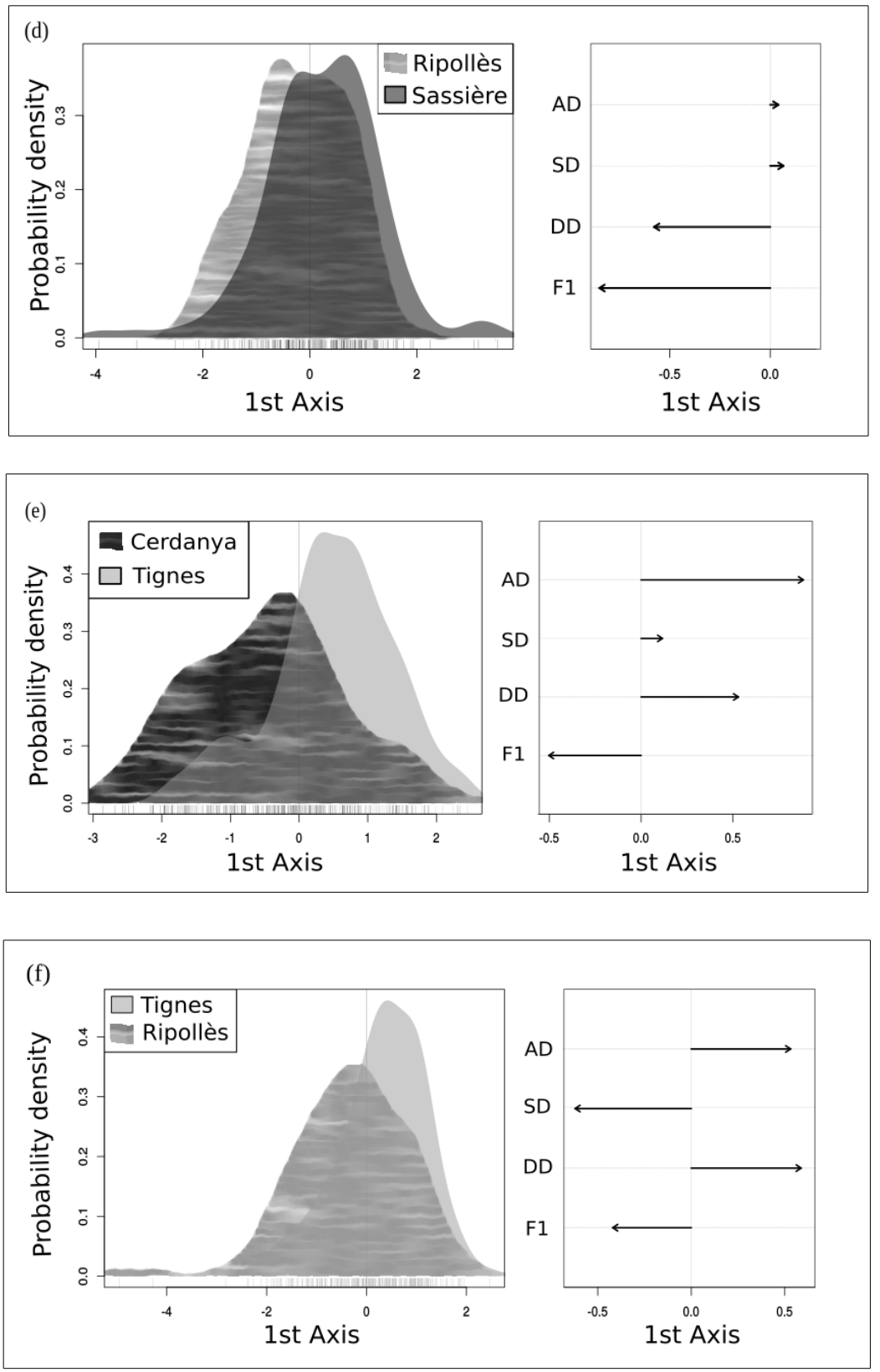


\section{Click here to access/download
Supplementary Material
Appendix S1.docx \\ Click here to access/download
Supplementary Material
Appendix S1.docx Click here to access/download
Supplementary Material
Appendix S1.docx

.




\section{Click here to access/download \\ Supplementary Material Appendix S2.docx

(a)




\section{Click here to access/download \\ Supplementary Material Appendix S3.docx}

(a)

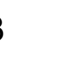

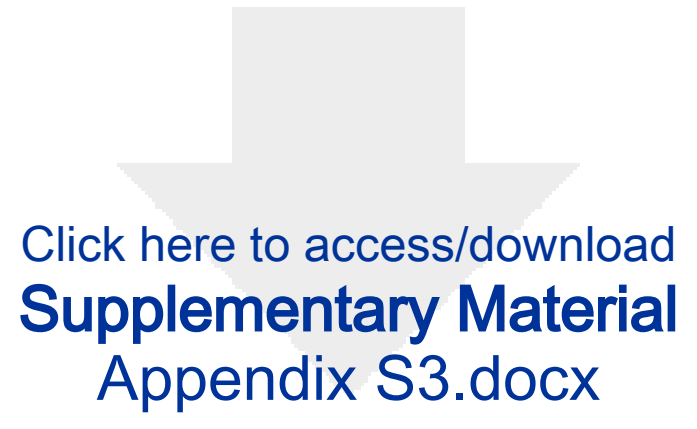

